\title{
LA LUCHA CONTRA LA EPIDEMIA DEL ZIKA, TENDENCIAS JURISPRUDENCIALES Y LA COOPERACIÓN REGIONAL EN EL ÁMBITO DE LA SALUD EN SUDAMÉRICA
}

THE FIGHT AGAINST THE ZIKA EPIDEMICS, TRENDS IN CASE LAW AND REGIONAL COOPERATION IN THE AREA OF HEALTH IN SOUTH AMERICA

\author{
A LUTA CONTRA A EPIDEMIA DO ZIKA. AS TENDÊNCIAS \\ JURISPRUDENCIAIS E A COOPERAÇÃO REGIONAL NO ÂMBITO \\ DA SAÚDE NA AMERICA DO SUL
}

Alberto Manuel Poletti Adorno

\section{Resumen}

Un insecto, Aedes Aegypti, invadió los países sudamericanos y es la causa de varias enfermedades. Mientras se avanza en el descubrimiento de una vacuna, el mecanismo más efectivo para combatir el avance del mal es la prevención y eliminación de criaderos. Mientras se discute sobre la necesidad de mejorar la legislación y los medios para hacer frente a la epidemia con limitados recursos del Estado, la jurisprudencia en varios países se pronuncia sobre una obligación amplia del Estado en materia de protección a la salud. Algunas alternativas son para mejorar la salud podría ser la cooperación internacional y los intercambios de información.

Palabras claves: Epidemia. Zika. Recursos del Estado. Sanciones penales. Derecho a la salud Cooperación Internacional.

\section{Abstract}

An insect, Aedes Aegypti, has invaded South America and it is the origin of different illness. While we advance in discovering a vaccine, the most effective tool for fight against the disease is prevention and the elimination of the 
places where the mosquito can develop. While it is discussed about the necessity of improving legislation and the ways to deal the epidemic with State's limited resources, the Courts has stated a wide obligation of the State in the field of health protection. Some alternatives for getting a better health service could be the use of regional cooperation and exchange of information.

Keywords: Epidemic. Zika. State resources. Criminal punishments. Right of health. International cooperation.

\section{Resumo}

Um inseto, Aedes Aegypti, invadiu os países da América do Sul e é a causa de varias doenças. Enquanto se avança no descobrimento da vacina, o mecanismo mais efetivo para combater o mal é a prevenção e eliminação dos lugares de reprodução dos mosquitos. Enquanto se analisa a necessidade de melhorar a legislação e os médicos para enfrentar a epidemia com os limitados recursos do Estado, a jurisprudência em vários países se pronuncia sobre a obrigação amplia do Estado em matéria de proteção à saúde. Algumas alternativas para a melhora da saúde poderiam ser a cooperação regional e os intercâmbios da informação.

Palavras-chaves: Epidemia. Zika. Recursos do Estado. Sanções penais. Direito à saúde. Cooperação internacional.

\section{INTRODUCCIÓN}

En el año 2015 se ha desarrollado con fuerza una nueva enfermedad, el Zika, causada por el mosquito Aedes Aegypti (transmisor igualmente del dengue y de la chikungunya). Este parásito ha causado estragos en varias regiones del planeta y se ha instalado con fuerza en Sudamérica.

Médicos brasileños lanzaron una voz de alarma durante el año 2014 y 2015 debido al aumento de casos de niños nacidos con microcefalia. Las autoridades sanitarias de varios Estados del noreste de ese país comunicaron la anormalidad a las autoridades nacionales. No fue sino luego de varios exámenes que se confirmó la aparición de una nueva dolencia, transmitida por mosquitos. ${ }^{1}$

Hoy en día sabemos que el mosquito se desarrolla en aguas es- 
tancadas y que la limpieza de las viviendas es esencial para prevenir la transmisión. No existe aún una vacuna por lo que la concientización en la eliminación de los criaderos es indispensable.

En el presente trabajo buscamos describir algunas de las medidas realizadas en el Paraguay y la región (I) para luego centrarnos en la necesidad de mejorar la cooperación regional (II) en lucha contra este flagelo que no distingue fronteras ni hace distinciones sociales, pudiendo afectar a todos.

\section{I) ACCIONES REALIZADAS EN LA REGIÓN}

Según informaciones del Ministerio de Salud Pública y Bienestar Social paraguayo "en el transcurso del 2015 (Enero a Diciembre) se han registrado 16.409 casos de Dengue confirmados; 4.289 casos confirmados de Chikungunya y se mantienen en 6 los casos de Zika en la ciudad de Pedro Juan Caballero, limítrofe con el Brasil aunque continúa la investigación de casos en otras zonas del país". ${ }^{2}$ El mosquito trasmisor de la enfermedad viene azotando al país desde hace varios años.

La realización de campañas de prevención no fue, lamentablemente, suficiente para frenar el avance del flagelo. Las comunidades, algunas municipalidades y especialmente los jóvenes organizaron mingas o jornadas de limpieza y desinfección en varios lugares.

Ante los pocos avances en la materia, es importante destacar la existencia de un precedente. El Defensor del Pueblo promovió un amparo en el año 2011 contra el Ministerio de Salud destacando que con el avance de la enfermedad, los recursos médicos oficiales fueron insuficientes y que debía atenderse a personas también en el eł sector privado. Un juez en lo laboral otorgó el amparo y dispuso que las personas afectadas puedan recurrir también a hospitales privados. ${ }^{3}$

Esta medida, como puede imaginarse, fue obviamente objeto de cuestionamientos por numerosos sectores. En tal sentido, posteriormente se aclaró el alcance de la resolución. Se estableció que la misma alcanzaba a personas con un cuadro clínico avanzado y que, previamente a recurrir a un establecimiento de salud privado, debían obtener una constancia 
emitida por un hospital del sector público de que no podían ser atendidos en dicho lugar. ${ }^{4}$ Igualmente se confirmó que los costos serían asumidos por el Estado.

No se trata de una práctica aislada en el Paraguay. Hemos destacado que la vía del amparo es una vía ya utilizada en anteriores ocasiones para hacer frente a problemas de la salud ante la inacción del Estado o de órganos autárquicos. ${ }^{5}$

Es importante destacar que las iniciativas para limitar el acceso a servicios de salud por motivos económicos han sido ampliamente criticadas por constituir una limitación inadecuada al derecho a la protección de la salud, un compromiso internacional asumido por los Estados. ${ }^{6}$

La vía judicial para hacer frente al derecho a la salud para casos de urgencia fue igualmente utilizada en la República Argentina en el caso Campodonico de Beviaqua y fue la Corte Suprema de Justicia la que, a partir del artículo 28 de la Convención americana sobre derechos humanos impuso al Estado la obligación de garantizar prestaciones básicas de salud pública cuando otros sectores privados y las propias provincias fallan en proveerlas. ${ }^{7}$

También en Colombia, ante la consulta de si una entidad encargada de garantizar la prestación de servicios ordenados por el médico tratante desconoce el derecho a la salud cuando no autoriza a una persona un servicio que requiere y no puede costearlo por si misma por el hecho de que no se encuentra incluido en el plan obligatorio de salud, la jurisprudencia del Tribunal constitucional en la Sentencia 760/2008 ha señalado claramente que el acceso a los servicios de salud que se requieran y estén contemplados en los planes obligatorios está garantizado constitucional y legalmente. ${ }^{8}$

Está claro que una epidemia puede tornar insuficientes los recursos previstos ordinariamente por un Estado y se requieren fondos adicionales. Pero también debe analizarse que otras medidas deben adoptarse en la lucha contra el mosquito transmisor de las enfermedades.

No se conocen casos de medidas judiciales que intimen a los particulares a abrir sus viviendas para permitir el acceso de funcionarios encargados del control y prevención.

No obstante, la existencia de terrenos abandonados hizo que algunos 
gobiernos municipales hayan tenido que intimar a los propietarios que figuran en el registro y ante la falta de respuesta, proceder a la limpieza de oficio de terrenos sin perjuicio de aplicar multas severas ${ }^{9}$. Expresó el Intendente de la ciudad de Villa Elisa, cercana a la capital que "en la zona existen unos 5.000 baldíos, pero la municipalidad solo cuenta con la capacidad para limpiar 1.000 predios" y que "ante la falta de respuesta de los dueños de baldíos, que pese a las continuas notificaciones realizadas a lo largo de los años no limpian sus propiedades, la comuna decidió encarecer el precio de la multa". ${ }^{10}$

El Ministerio Público señaló inicialmente que intervendría solo en casos de emergencia y a solicitud del Ministerio de Salud Pública o de autoridades. ${ }^{11}$ Pero ante el avance de la enfermedad decidió acompañar los procedimientos administrativos. Se explicó que las omisiones de limpieza pueden generar persecuciones penales de oficio y aplicar sanciones. Así, se mencionó que conforme al art. 10 de la Ley 716/1996 "al negarse a cooperar, [los propietarios de terrenos baldíos abandonados] se exponen a ser sancionados con penitenciaría de 6 a 18 meses o multa de 100 a 500 jornales mínimos legales ( $G$. 35 millones) para actividades diversas no especificadas" y que en el ámbito municipal "la Ordenanza 408/14 de Basura Cero establece multas que van de los 20 jornales (G. 1.404.000) a los 2.700 jornales ( $G .189$ millones). Estas son aplicadas según cada caso, sumándose una posible condena de 5 años de pena privativa de libertad".12

Es importante destacar la necesidad de reformar el marco penal vigente. La norma que sirve de base a los procesos dispone:

Artículo 10.- Serán sancionados con penitenciaría de seis a dieciocho meses y multa de 100 (cien) a 500 (quinientos) jornales mínimos legales para actividades diversas no especificadas:

c) Los que injustificadamente se nieguen a cooperar en impedir o prevenir las violaciones de las regulaciones ambientales, o los atentados, accidentes, fenómenos naturales peligrosos, catástrofes o siniestros.

El Fiscal del Medio Ambiente mencionó que "no existe una ley que tipifique la falta de limpieza en los hábitos del ciudadano".13 Según el art. 168 de la Constitución las cuestiones de urbanismo, ambiente, educación, 
asistencia sanitaria y social, cuerpos de inspección y de policía son de competencia municipal, sin que ello implique que el gobierno central cede sus prerrogativas ya que la República del Paraguay es un Estado unitario y descentralizado conforme al art. 1 de la Constitución.

Por tal motivo, tanto los gobiernos municipales como las autoridades nacionales deberían analizar las medidas para hacer frente a la pandemia causada por el mosquito, lo que debe incluir una modificación de la legislación para prever la sanción a conductas de omisión que ensucien un lugar sin entrar a analizar si existe o no justificación. Si bien al momento de analizar la reprochabilidad puede moderarse la pena, es importante destacar que un abandono del lugar por poco tiempo no es lo mismo que una omisión continua de la obligación de mantener limpio un predio. Pero a la vez, consideramos necesaria la instauración de un sistema de registro de datos e intercambio de informaciones que debe ser accesible, por medio de la cooperación internacional.

\section{II) LA COOPERACIÓN REGIONAL: UNA VÍA ÚTIL Y NECE- SARIA EN LA LUCHA CONTRA LOS FLAGELOS CAUSADOS POR EL AEDES AEGYPTI}

Hemos mencionado que los mosquitos, lamentablemente, salieron del continente africano (el Zika fue descubierto en África en 1947) y luego de avanzar a algunas islas en la Polinesia y Asia llegaron a América ${ }^{14}$. El ejemplo de la comunicación efectuada por las autoridades del noreste brasileño es un testimonio claro de la necesidad de compartir información.

Hoy en día, la alerta epidemiológica obliga a los países a mantener registros actualizados de las enfermedades y fácilmente puede compartirse información. Sin embargo, los avances técnicos y descubrimientos en la lucha contra estas enfermedades aún son discutidos principalmente en el ámbito académico.

Es necesario la cooperación regional avance para permitir trabajos y análisis conjuntos entre personas que se hallan separados por la geografía pero unidos en la lucha contra el Aedes Aegypti. De hecho, este punto fue destacado en la II Reunión Extraordinaria de Ministros y Ministras del 
Mercosur y Estados Asociados del MERCOSUR, UNASUR y otros países latinoamericanos que se desarrolló el día 3 de febrero de 2016 en Montevideo, Uruguay ante la grave situación epidemiológica derivada del Zika. La declaración contiene 16 puntos: ${ }^{15}$

1) Readecuar a partir de las experiencias adquiridas las estrategias de gestión integrada de dengue a otras enfermedades transmitidas por el vector, como medida principal para enfrentar la epidemia regional.

2) Fortalecer el rol de la autoridad sanitaria para coordinar la respuesta integrada a la epidemia, que involucre a todos los niveles del gobierno y garantice el alcance nacional de la misma. Esto podrá implicar la necesidad de disponer de presupuestos adicionales.

3) Ratificar en ese sentido, el valor significativo que el comportamiento de la población tiene para garantizar el éxito de todo tipo de campaña encaminada a controlar y prevenir al vector.

4) Diseñar y ejecutar campañas de educación para el control vectorial, dirigidas a la preparación de la población, fomentando su conocimiento y adhesión a las acciones de salud pública y compartir experiencias exitosas entre los países.

5) Fortalecer los mecanismos de comunicación que posibiliten una información precisa y actualizada de la situación epidemiológica, notificando los riesgos sanitarios de acuerdo a lo establecido en el Reglamento Sanitario Internacional.

6) Establecer un sistema de información de fácil acceso, en los puertos, aeropuertos y pasos de frontera, que orienten a los ciudadanos sobre las medidas de prevención y control que están desarrollando los países de acuerdo a su situación epidemiológica.

7) Coordinar las acciones para adecuar la respuesta de salud pública para la vigilancia y control de las enfermedades trasmitidas por el vector: Dengue, Chikungunya y Zika.

8) Generar capacidades y apoyo recíproco para el diagnóstico epidemiológico, clínico y laboratorial de casos de Zika.

9) Considerar la inclusión en las rondas de negociación de compras conjuntas de medicamentos de alto costo, aquellos necesarios para el tratamiento del síndrome de Guillain- Barré.

10) Fomentar acciones permanentes y colaborativas para generación de conocimiento por medio de investigación y desarrollo de nuevas tecnologías para el diagnóstico, prevención y tratamiento de la infección por el Zika y sus consecuencias sobre la salud de la población.

11) Diseñar protocolos y directrices clínicas para el tratamiento de las enfermedades trasmitidas por el vector y sus consecuencias.

12) Contribuir a la actualización del personal de salud en la prevención y 
tratamiento de las infecciones causadas por los virus Zika, Dengue y Chikungunya.

13) Fortalecer la atención primaria con servicios de atención integral en el neonato y primera infancia, con énfasis en la estimulación precoz de los niños y niñas con microcefalia.

14) Promover la cooperación horizontal, sur-sur entre los países de la región en estrecha articulación con la OPS/OMS quien se compromete en elaborar protocolos y directrices técnicas en diferentes áreas, como vigilancia, comunicación de riesgo y manejo clínico de pacientes, a través de la conformación de un equipo de expertos de la región. En tal sentido, la Directora de OPS/OMS asume en esta reunión el compromiso de apoyar estas líneas de acción.

15) Solicitar a la Cooperación Internacional la orientación de recursos que fortalezcan las acciones previstas en la estrategia definida en el marco de la presente Declaración.

16) Crear un Grupo Ad Hoc de seguimiento de la emergencia, dependiente de la Reunión de Ministros de Salud (RMS) para estudiar, monitorear y establecer las recomendaciones que correspondan. Este Grupo estará coordinado por la Presidencia Pro Tempore en ejercicio y rendirá su primer informe en la próxima Reunión Ordinaria de Ministros de Salud del MERCOSUR.

Es importante destacar la iniciativa novena que se refiere a la compra conjunta de medicamentos de alto costo, una experiencia ya decidida anteriormente en el marco de la lucha contra el cáncer, el Sida y la hepatitis en la región y que permitió ahorrar costos a los países ya que el precio de venta obtenido en conjunto fue mucho menor. ${ }^{16}$

El acuerdo reconoce igualmente el rol de la sociedad en la prevención de los flagelos y el fortalecimiento de la atención primaria buscando evitar que embarazadas contraigan el virus y den a luz a niños y niñas con microcefalia.

Algunos países han recomendado a sus habitantes demorar los embarazos mientras que otros sectores se pronunciaron a favor del aborto en estos casos. Se debe señalar que ante la falta de uniformidad de las legislaciones de los países de la región en estos casos, no cabe duda que es conveniente destinar recursos necesarios y adicionales para hacer frente a la prevención y tratamiento antes que discutir sobre propuestas que requieren modificaciones constitucionales y legales que pueden 
resultar controvertidas.

Hemos tenido experiencias en la colocación en terminales aéreas, portuarias y terrestres de carteles explicando los síntomas de enfermedades y la necesidad de consultar con profesionales médicos ante la aparición de los mismos. Sin embargo, el caso del Zika plantea desafíos adicionales. Durante la realización de los Juegos Olímpicos en Rio de Janeiro en 2016 se generó nuevamente un importante desplazamiento de personas al continente y se pudo reflexionar sobre el tiempo que las personas afectadas deben seguir un tratamiento mínimo antes de continuar su viaje o volver a los países donde residen. Las alertas de viajes y consejos emitidos por los Ministerios de Relaciones Exteriores que invitaron a los ciudadanos a evitar dirigirse a determinados sectores fueron tomadas por los órganos de seguridad social para evitar hacerse cargo del reembolso de ciertas enfermedades. Por ello, la información que fue proporcionada a turistas incluyó lugares donde podría realizarse el control de salud y donde acudir, preferiblemente con números telefónicos gratuitos y accesibles desde Internet o por medio de teléfonos en distintos países.

Hace algunos años, autoridades mexicanas criticaban la suspensión de vuelos desde países americanos hacia su territorio en ocasión de la pandemia de la influenza. ${ }^{17}$ Se reconoció el legítimo interés de las autoridades de evitar el contagio pero se discrepó con el método escogido para combatir el avance de la enfermedad. Con la cooperación internacional y el reconocimiento de la situación de emergencia por los países de la región, podrá estimarse que los Estados deben destinar recursos para los habitantes que se encuentran en tránsito basándose no solo en la reciprocidad sino principalmente en el sentimiento de humanidad. Los recursos no deben ser solo monetarios sino también de intercambio y difusión de la información existente.

\section{CONCLUSIÓN}

Consideramos que la declaración emitida por las autoridades de los países latinoamericanos en materia de salud constituye un importante avance en la lucha contra las enfermedades transmitidas por el Aedes 
Aegypti, pero que ello debe ser acompañado con la disponibilidad de los medios económicos necesarios para la prevención y el tratamiento de la enfermedad.

Las experiencias de un país deben ser compartidas y en la situación actual existen medios para que ello se realice. Es importante que la sociedad contribuya a generar espacios en tal sentido y las universidades han sido tradicionalmente lugares de discusión e intercambio de información en momentos en los que los gobiernos se encuentran siempre carentes de fondos suficientes.

Los vínculos que ofrece una sociedad globalizada en el ámbito del intercambio de información deben ser aprovechados. Así como se discutió en sede judicial la posibilidad de ingresar a viviendas particulares para limpieza, creemos que podrán desarrollarse dos contenciosos: la privación temporaria de la libertad de desplazamiento en casos avanzados de enfermedad y la entrega de información sobre el estado de salud de una autoridad pública a la de otro país. En el primer caso, ello se justifica atendiendo a la necesidad de preservar la vida del paciente que puede verse forzado a cancelar sus planes originales. En el segundo caso, es importante destacar que la transmisión para fines estadísticos y de investigación debe hacerse en forma confidencial y que a los fines del tratamiento de una persona en otro país, resulta importante efectuar la remisión completa de datos. Ello resulta de interés del paciente y de la comunidad.

\section{NOTAS}

1 McNEIL Jr, Donald; ROMERO, Simon y TAVERNISE, Sabrina: How a medical mystery in Brazil led Doctors to Zika, New York Times, Health, 6 de febrero de 2016. http://www.nytimes. com/2016/02/07/health/zika-virus-brazil-how-it-spread-explained.html?_r=0

2 Portal Paraguay.com: Inminente epidemia nacional de dengue, 7 de febrero de 2016. http:// www.paraguay.com/nacionales/inminente-epidemia-nacional-138534

3 Página del Poder Judicial de la República del Paraguay, Juez ordena a los hospitales privados a recibir a los pacientes con dengue, 5 de abril de 2011 http://www.pj.gov.py/notas/5145-juez-ordena-a-los-hospitales-privados-a-recibir-a-los-pacientes-con-dengue

4 Diario ABC Color: "Enfermos no deben acudir directamente a centros privados", Nacionales, 30 de marzo de 2011. Entrevista al Juez Tadeo Zarratea. http://www.abc.com.py/nacionales/ enfermos-de-dengue-no-deben-acudir-directamente-a-centros-privados-aclaran-238706.html

5 POLETTI ADORNO, Alberto Manuel: "El derecho a la salud: los límites entre lo público y lo privado », Revista latinoamericana de derechos humanos, Universidad de San José de Costa Rica, Volumen 
23 (1), I Semestre 2012 (ISSN: 1659-4304), p. 59-71. Disponible en: http://www.revistas.una. ac.cr/index.php/derechoshumanos

6 AGUADO I CUDOLÀ, Vicenç: "Derecho a la protección de la salud y exclusión de la asistencia sanitaria: la crisis económica como pretexto para la limitación del acceso a los servicios y prestaciones del estado del bienestar", Revista Vasca de Administración Pública. Herri-Arduralaritzako Euskal Aldizkaria, ISSN 0211-9560, № 99-100, 2014 (Ejemplar dedicado a: Homenaje a Demetrio Loperena y Ramón Martín Mateo), págs. 87-110

7 ABRAMOVICH, Víctor y PAUTASSI, Laura: “El derecho a la salud en los tribunales. Algunos efectos del activismo judicial en el sistema de salud en Argentina", Salud colectiva, ISSN 1669-2381, Vol. 4, №. 3, 2008, págs. 261-282

8 ESPINOSA TORRES, Ximena: "El derecho fundamental a la salud en Colombia: base teórica y jurisprudencial”, Saber, ciencia y libertad. ISSN 1794-7154, 2013, Vol. 8, N 1, p. 45-59. El texto de la sentencia está disponible en: http://www.corteconstitucional.gov.co/ relatoria/2008/T-760-08.htm

9 Diario Hoy: “Comuna avisa que multará a vecinos puercos", Nacionales, $1^{\circ}$ de febrero de 2016. http://www.hoy.com.py/nacionales/comuna-avisa-que-multara-a-vecinos-puercos

10 Diario Hoy: "Propietarios de baldíos se exponen a millonarias multas", Nacionales, 13 de enero de 2015. http://www.hoy.com.py/nacionales/propietarios-de-baldios-se-exponen-a-millonarias-multas

11 Diario Última Hora” “Fiscalía intervendrá predios solo si hay emergencia”, País, 12 de marzo de 2012. http://m.ultimahora.com/dengue-fiscalia-intervendra-predios-solo-si-hay-emergencia-n510446.html

12 Ministerio Público de la República del Paraguay: "Fiscalía sigue interviniendo baldíos sucios y en los que pululan criaderos del mosquito que transmite el dengue", Noticias, 27 de enero de 2016. http://www.ministeriopublico.gov.py/fiscalia-sigue-interviniendo-baldios-sucios-y-en-los-que-pululan-criaderos-del-mosquito-que-transmite-el-dengue-n1391

13 Portal Paraguay.com: “No descartan declarar emergencia para la lucha contra el dengue”, Asunción, 19 de marzo de 2012. http://otaku.yagua.com.py/salud-y-educacion/no-descartan-declarar-emergencia-para-la-lucha-contra-el-dengue-80988?ep=true

14 McNEIL Jr, Donald, op. cit. New York Times, 6 de febrero de 2016. En el mismo sentido ROMERO, Cecilia; DELFINO, Marcos, GIACHETTO, Gustavo y PIREZ, María Catalina: "Dengue: frente a una eventual epidemia en Uruguay. Puesta al día", Clínicas Pediátricas del Sur, Vol. 2. 2008, p. 29 http://www.sup.org.uy/web2/clinicas-del-sur/vol-2/pdf/clinicas\%20del\%20sur_02_4.pdf

15 Texto completo: Ministerio de Salud de la República Oriental del Uruguay. http://www.msp.gub. uy/noticia/declaraci\%C3\%B3n-conjunta

16 Diario La Nación: Ministros de Salud del MERCOSUR analizaron compra conjunta de medicamentos de alto costo, Asunción, 13 de noviembre de 2015. http://www.lanacion.com.py/2015/11/13/ ministros-de-salud-del-mercosur-analizaron-compra-conjunta-de-medicamentos-de-alto-costo/ Texto en idioma portugués: Conselho Regional de Farmácia do Estado de Santa Catarina, 16 de noviembre de 2015. http://crfsc.gov.br/mercosul-fara-compra-comum-de-medicamento-contra-a-aids/

17 El Economista: “México critica a países que cancelan vuelos por influenza”, Internacional, 2 de mayo de 2009. Según la noticia, la medida fue dispuesta por autoridades de Argentina, Ecuador, Perú, Cuba y China. http://eleconomista.com.mx/notas-online/internacional/2009/05/02/ critica-mexico-paises-que-cancelan-vuelos-influenza

\section{BIBLIOGRAFIA}

II Reunión Extraordinaria de Ministros y Ministras del Mercosur y Estados Asociados del MERCOSUR, UNASUR y otros países latinoamericanos Acta del 3 de febrero de 2016 en Montevideo, Uruguay Texto completo: Ministerio de 
Salud de la República Oriental del Uruguay http://www.msp.gub.uy/noticia/ declaraci\%C3\%B3n-conjunta

ABRAMOVICH, Víctor y PAUTASSI, Laura: "El derecho a la salud en los tribunales. Algunos efectos del activismo judicial en el sistema de salud en Argentina", Salud colectiva, ISSN 1669-2381, Vol. 4, №. 3, 2008, págs. 261-282

AGUADO I CUDOLÀ, Vicenç: “Derecho a la protección de la salud y exclusión de la asistencia sanitaria: la crisis económica como pretexto para la limitación del acceso a los servicios y prestaciones del estado del bienestar", Revista Vasca de Administración Pública. Herri-Arduralaritzako Euskal Aldizkaria, ISSN 02119560, № 99-100, 2014 (Ejemplar dedicado a: Homenaje a Demetrio Loperena y Ramón Martín Mateo), págs. 87-110

CASCO VERÓN, Atilio: "Análisis de la seguridad social en Paraguay", 2009. Internet: http://white.oit.org.pe/spanish/260ameri/oitreg/activid/proyectos/ actrav/proyectos/proyecto_ssos/act_paises/paraguay/documentos/asuncion_mar2009/taller_integracion.ppt

Diario ABC Color: "Enfermos no deben acudir directamente a centros privados", Nacionales, 30 de marzo de 2011. Entrevista al Juez Tadeo Zarratea. http://www. abc.com.py/nacionales/enfermos-de-dengue-no-deben-acudir-directamente-acentros-privados-aclaran-238706.html

Diario Hoy: "Comuna avisa que multará a vecinos puercos", Nacionales, $1^{\circ}$ de febrero de 2016. http://www.hoy.com.py/nacionales/comuna-avisa-quemultara-a-vecinos-puercos

Diario Hoy: "Propietarios de baldíos se exponen a millonarias multas", Nacionales, 13 de enero de 2015. http://www.hoy.com.py/nacionales/propietariosde-baldios-se-exponen-a-millonarias-multas

Diario La Nación: Ministros de Salud del MERCOSUR analizaron compra conjunta de medicamentos de alto costo, Asunción, 13 de noviembre de 2015. http://www. lanacion.com.py/2015/11/13/ministros-de-salud-del-mercosur-analizaroncompra-conjunta-de-medicamentos-de-alto-costo/

Texto en idioma portugués: Conselho Regional de Farmácia do Estado de Santa Catarina, 16 de noviembre de 2015. http://crfsc.gov.br/mercosul-fara-compracomum-de-medicamento-contra-a-aids/

Diario Última Hora” “Fiscalía intervendrá predios solo si hay emergencia”, País, 
12 de marzo de 2012. http://m.ultimahora.com/dengue-fiscalia-intervendrapredios-solo-si-hay-emergencia-n510446.html

El Economista: "México critica a países que cancelan vuelos por influenza", Internacional, 2 de mayo de 2009. Según la noticia, la medida fue dispuesta por autoridades de Argentina, Ecuador, Perú, Cuba y China.

ESPINOSA TORRES, Ximena: "El derecho fundamental a la salud en Colombia: base teórica y jurisprudencial", Saber, ciencia y libertad. ISSN 1794-7154, 2013, Vol. 8, N 1, p. 45-59

McNEIL Jr, Donald; ROMERO, Simon y TAVERNISE, Sabrina: How a medical mystery in Brazil led Doctors to Zika, New York Times, Health, 6 de febrero de 2016. http://www.nytimes.com/2016/02/07/health/zika-virus-brazil-how-itspread-explained.html?_r=0

Ministerio Público de la República del Paraguay: "Fiscalía sigue interviniendo baldíos sucios y en los que pululan criaderos del mosquito que transmite el dengue", Noticias, 27 de enero de 2016. http://www.ministeriopublico.gov.py/ fiscalia-sigue-interviniendo-baldios-sucios-y-en-los-que-pululan-criaderos-delmosquito-que-transmite-el-dengue-n1391

Poder Judicial de la República del Paraguay, Juez ordena a los hospitales privados a recibir a los pacientes con dengue, 5 de abril de 2011 http://www.pj.gov.py/ notas/5145-juez-ordena-a-los-hospitales-privados-a-recibir-a-los-pacientescon-dengue

POLETTI ADORNO, Alberto Manuel: "El derecho a la salud: los límites entre lo público y lo privado », Revista latinoamericana de derechos humanos, Universidad de San José de Costa Rica, Volumen 23 (1), I Semestre 2012 (ISSN: 1659-4304), p. 59-71. Disponible en: http://www.revistas.una.ac.cr/index.php/ derechoshumanos

Portal Paraguay.com: Inminente epidemia nacional de dengue, 7 de febrero de 2016. http://www.paraguay.com/nacionales/inminente-epidemia-nacional-138534

Portal Paraguay.com: "No descartan declarar emergencia para la lucha contra el dengue", Asunción, 19 de marzo de 2012. http://otaku.yagua.com.py/salud-yeducacion/no-descartan-declarar-emergencia-para-la-lucha-contra-el-dengue80988?ep=true 
ROMERO, Cecilia; DELFINO, Marcos, GIACHETTO, Gustavo y PIREZ, María Catalina: "Dengue: frente a una eventual epidemia en Uruguay. Puesta al día", Clínicas Pediátricas del Sur, Vol. 2. 2008, p. 28-38 http://www.sup.org.uy/web2/ clinicas-del-sur/vol-2/pdf/clinicas\%20del\%20sur_02_4.pdf

SAPENA, Josefina: "Jurisprudencia constitucional", Intercontinental Editora, 793 p. 2000

Artigo recebido em: 2-10-2017

Autor convidado

\section{Alberto Manuel Poletti Adorno}

Doctor en Derecho de la Escuela de Derecho Comparado en la Universidad París 1 Panthéon-Sorbonne (2007). Graduado en Abogacía en la Facultad de Derecho y Ciencias Sociales de la Universidad Nacional de Asunción. Egresado de la Escuela Judicial paraguaya. Actualmente se desempeña como Abogado en el sector privado. Es Profesor de la Universidad Columbia del Paraguay e Investigador Externo del Dpto. de Derecho Político de la Universidad Nacional de Enseñanza a Distancia (UNED) en España. Las opiniones aquí expresadas son estrictamente personales y solo comprometen al autor. Correo-e: alberto_ poletti@hotmail.com

Universidad Columbia del Paraguay 25 de Mayo $\mathrm{N}^{\circ} 658$ y Antequera. Asunción. Paraguai. 